\title{
EL CURRICULO SOCIAL: UNA NECESIDAD DE LOS PEI
}

\author{
POR \\ ALVARO AVENDAÑO \\ PROFESOR UNIVERSIDAD SURCOLOMBIANA
}

1

NECESIDAD DEL CURRICULO SOCIAL:

\subsection{PARA LA GESTION EN LA ESCUELA:}

En el diseño de los PEI existen tres grupos: alumnos, padres de familia, profesores y egresados que participan en el PEI. Pero qué cómo podrán participar los padres de familia y egresados sin una identidad como comunidad o sin una preparación adecuada en cuestiones pedagógicas? Cómo garantizar que el proyecto educativo institucional sea realmente un producto de la comunidad educativa y no sólo de los educadores, los directivos docentes y los administradores escolares? ${ }^{1}$.

La respuesta a esta gestión se puede dar a través de un programa extramuros de las intituciones educativas a nivel municipal que se llama el CURRICULO SOCIAL:

1 Mejía Botero, William. Proyecto Educativo Institucional. Actualidad educativa. Rev el educador/ edición no 25. Editorial Norma.
A través del él la comunidad podrá recibir orientaciones sobre la calidad, cantidad y características de los PEI de las instituciones.

Se podrá gestionar en forma conjunta por el establecimiento con las entidades gubernamentales y no gubernamentales, especializadas en la atención a las familias y comunidades los programas de servicio social estudiantil.

También podrá participar en la evaluación de la institución, la cuál será realizada por el Consejo Directivo Institucional siguiendo criterios y objetivos preestablecidos por el MEN (ART 84 DE LA LEY 115 DE 1994). Aquí es importante el proceso de cómo la institución se ha adaptado a las situaciones y necesidades del educando, la comunidad local, regional y nacional.

Y por último la comunidad aprenderá a gestionar en los otros organismnos educativos: Los NUCLEOS EDUCATIVOS, los JUNE, JUDE, JUME y los FOROS EDUCATIVOS: 
1.2 PARA PARTICIPAR EN LA VIDA CIUDADANA: DESCENTRALIZACION Y LA GESTION AMBIENTAL

En la ley 136 de 1994 de municipalización se contempla la participación de la comunidad en la administración municipal. En este proceso de descentralización administrativa, política y fiscal de la planificación se pretende crear las bases para la participación regional y local en la gestión del desarrollo social, económico y ambiental.

La gestión ambiental como actividad de los ciudadanos se realiza en una estructura urbana, la cual, debe ser entendida como un conjunto de elementos que sirven de soporte material a las actividades ciudadanas, no es simplemente una estructura dual campo-ciudad, sino más bien una extensa red de captación de excedentes, que acaba concentrándose en el sector financiero, industrial e inmobiliario. Del campo fluyen hacia la ciudad los excedente económicos, la mano de obra y los recursos naturales. ${ }^{2}$

El currículo social nos dotará de una estructura y un lenguaje para el diálogo. Si se usan símbolos y estructuras que concuerdan con las de las comunidades ${ }^{3}$.

\section{SOPORTES DE LEY PARA EL ESTABLECIMIENTO DEL CURRICULO SOCIAL:}

La ley 115 de 1994 es un gran soporte:

El ART 43 define la educación informal: conocimientos no estructurados provenientes de personas, instituciones, etc.
En el ART 44 se colocan los medios de comunciación al servicio de la educación. En el ART 45 se crea el Sistema Nal de educación masiva. Para satisfacer la educación continuada, de validación para la educación formal y de difusión artística y cultural. El programa se ejecutará con el uso de medios electrónicos de comunicación - transmisión de datos, tales como radiodifusión, la televisión, la temática o cualquier otro que utilice el espectro electromagnético.

La ley contempla la educación de adultos, no necesariamente para la obtención de títulos (ART 50 DE LA LEY 115 DE 1994), sino que presenta objetivos específicos como (ART 51 DE LA LEY 115 DE 1994): Desarrollar la capacidad de participación en la vida económica, política, social, cultural y comunitaria.

\section{SECRETARIA TECNICA DEL PROGRAMA NACIONAL DE ESTUDIOS AMBIENTALES. Manizales. 1993. p38}

